\section{Head Injury Management Pro- tocols: One Year Retrospective Analysis}

\begin{abstract}
Ali Al Mashani, Neeraj Salhotra*, Arshad Kabir Khan, Mohammad Hadad, Bashar Al Tunbi and Mohammad Hashim
\end{abstract}

Khoula Hospital, Muscat, Oman

\begin{abstract}
Head injury is the biggest challenge for management in all societies to safeguard the most productive age group, the youth. All management protocols aim to get maximum outcome for increased survival in head injuries. Severe head injuries are the challenge for all neurosurgeons. Conservative and surgical managements are offered as per the imaging. Intracranial pressure monitoring is the key factor in deciding surgical intervention requirement. Department of Neurosurgery, Khoula Hospital, Muscat presents their one year analysis for various management protocols adopted. Results revealed a good outcome in minor head injuries, fair in moderate head injuries and worst in severe head injuries. Study analyzed a total of 432 patients of head injuries and was managed after triaging them in various categories as per internationally accepted protocols.
\end{abstract}

Keywords: GCS; Head injury; ICP

\section{Introduction}

Head injury is the most common cause of morality in the young. Head injury management is crucial for good outcome. Early intervention is important for prevention of secondary damage to brain and hence perfect triage at the accident and emergency department and early recognition of the head injury after ruling out other associated

*Corresponding author: Neeraj Salhotra, Khoula Hospital, Muscat, Oman, Tel: +968 95394198; E-mail: neersal@hotmail.com

Citation: Mashani AA, Salhotra N, Khan AK, Kislykov AN, Hadad M, et al. (2018) Head Injury Management Protocols: One Year Retrospective Analysis. J Emerg Med Trauma Surg Care 5: 025

Received: July 16, 2018; Accepted: August 29, 2018; Published: September 13,2018

Copyright: (C) 2018 Mashani AA, et al. This is an open-access article distributed under the terms of the Creative Commons Attribution License, which permits unrestricted use, distribution, and reproduction in any medium, provided the original author and source are credited. injuries is the aim. Early neurosurgical reference after the scan and patient stabilization amounts to a good outcome. In our institution one year retrospective analysis of head injury patients was analyzed and outcome is presented here with.

\section{Material and Methods}

A retrospective study was done analyzing 1 year data of patients of head injury admitted in our department. All patients were triaged in the emergency department and depending upon Glasgow Coma Scale was divided into major broad groups. GCS of 14 to 15 were ascribed minor head injury group. GCS of 9 to 13 were put in moderate head injury category. If GCS was 8 or less severe head injury was labeled. All patient after initial $\mathrm{ABC}$ viz airway, breathing and circulation analysis and management underwent CT brain for head injury status. GCS of 8 and below were electively intubated ventilated without paralyzing as per international standards and only deeply sedating [1].

Surgical categories were given. Patients with epidural hematoma (Figure 1), subdural hematoma, and intracerebral contusions, compound depressed fractures (Figure 2) or massive unilateral brain injury causing mass effect and midline shift were the candidates in this group. Any patient with midline shift, poor GCS and pupillary changes were wheeled straight into operating room.

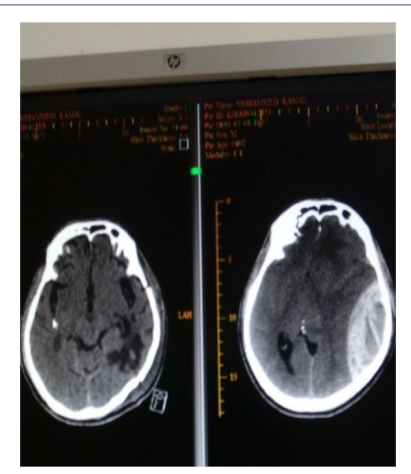

Figure 1: Pre and post op images of a case of epidural hematoma.

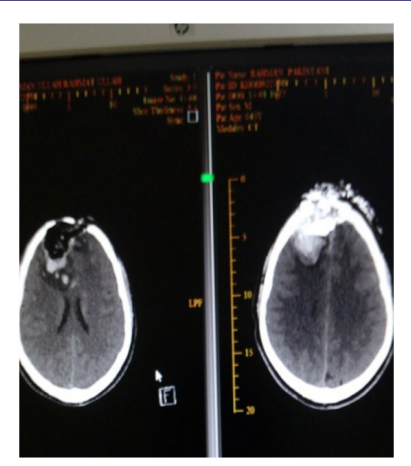

Figure 2: Pre and Post op images of compound depressed fracture. 
Patients with diffuse axonal injuries, brain edema with GCS less than 8 were candidates where a ICP (Intracerebral Pressure Monitoring) or EVD (External Ventricular Drain) probe was inserted (Figure $3)$.

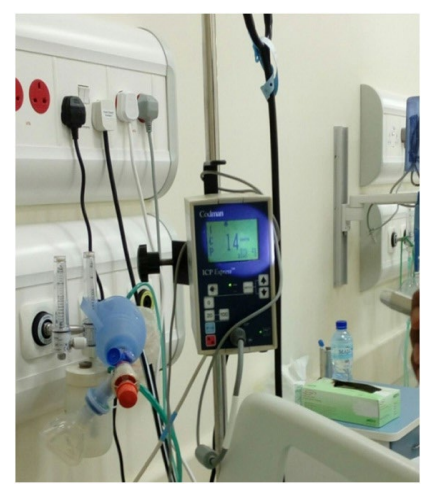

Figure 3: ICP monitoring.

If ICP was more than 20 it required measures to decrease ICP by hyperventilation, head end elevation, CSF drainage via opening the EVD (if placed) and anti edema measures say mannitol, furosemide or $3 \%$ saline infusion, were initiated $[1,2]$.

Craniotomy and evacuation of epidural or acute subdural hematomas were done. Craniotomy and evacuation of large intracerebral contusions with mass effects were done. Wound debridements with dural repair were done for compound depressed fractures.

Large decompressive craniotomies with duraplasty were done if there was unilateral diffuse brain swelling with midline shift (Figures 4-6). Bone flaps were replaced later if patients improve.

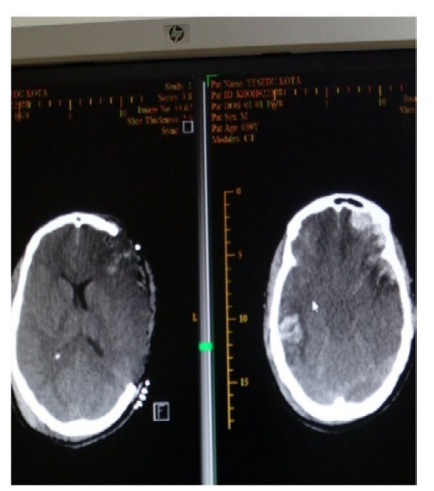

Figure 4: Decompressive craniectomy in contusions.

CSF rhinorrheas were initially treated conservatively if persists lumbar drains were placed to encourage skull base healing for a week. If still persists then CT cisternography was done and a planned surgical closure of bony defect were done if transnasal endoscopic repair of the defect fails by ENT colleagues.

Chronic subdural hematoma developed in set of patients and later required burr hole evacuation for the same.
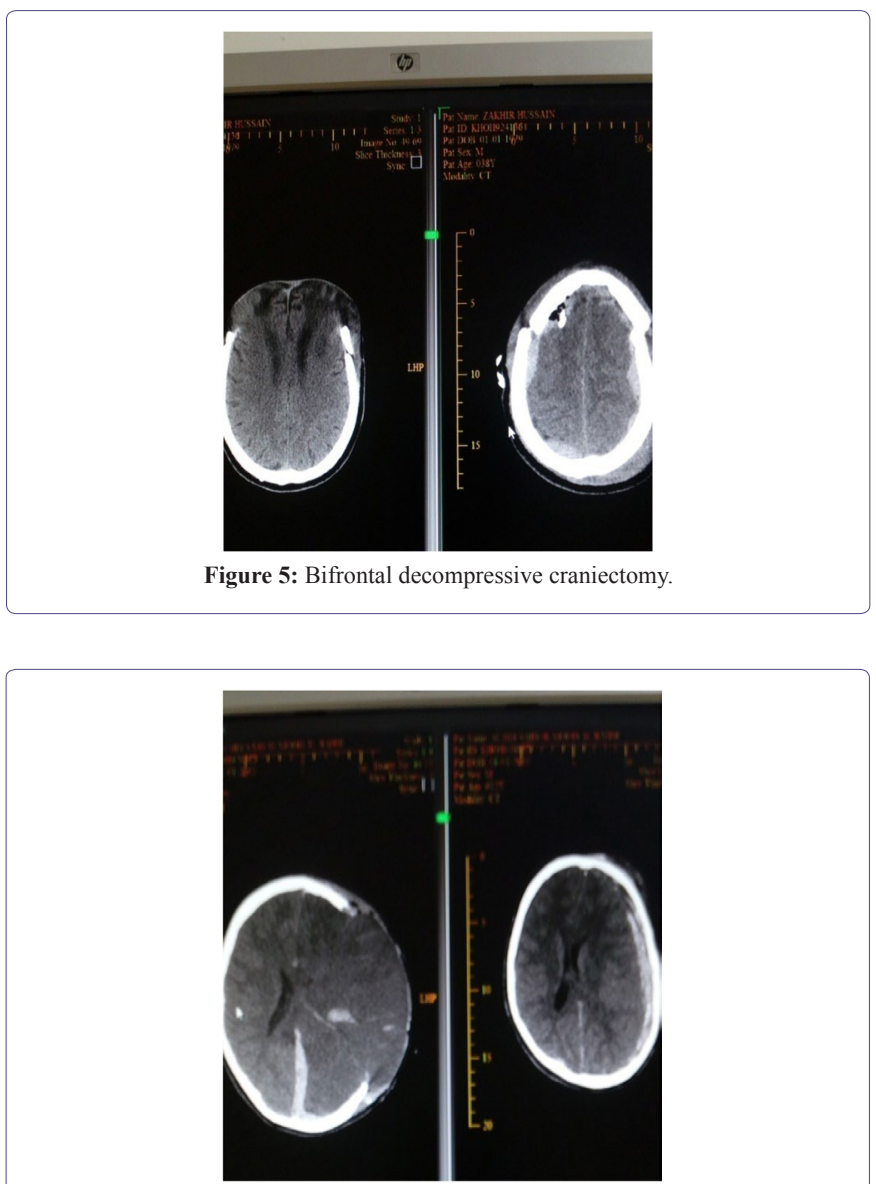

Figure 6: Decompressive craniectomy in a case of acute subdural hematoma.

\section{Results}

Total 432 patients were admitted with head injury in year 2017. Out of that 302 were in the minor head injury group. 63 patients were given moderate head injury group. 67 severe head injury patients were seen in year 2017 table 1 .

\begin{tabular}{|c|c|c|c|}
\hline S. No & Type of Head Injury & No of Cases \\
\hline 1 & Minor Head Injury & 302 \\
\hline 2 & Moderate Head Injury & 63 \\
\hline 3 & Severe Head Injury & 67 \\
\hline Total & 432 \\
\hline
\end{tabular}

Out of these cases 196 were children below age of 12 years and 230 cases were adults table 2 .

\begin{tabular}{|c|c|}
\hline Age Group & No \\
\hline 0 to 12 yrs & 196 \\
\hline$>12$ yrs & 230 \\
\hline
\end{tabular}

Table 2: Age distribution. 
Out of these 432 patients 303 were males and 129 were females table 3 .

\begin{tabular}{|c|c|}
\hline Sex Group & No \\
\hline Males & 303 \\
\hline Females & 129 \\
\hline \multicolumn{2}{|c|}{ Table 3: Sex distribution. } \\
\hline
\end{tabular}

Out of all these cases 228 had fall as mode of injury, 147 patients had road traffic accident as mode of injury and 57 patients had other miscellaneous causes table 4 .

\begin{tabular}{|c|c|}
\hline Mode of Head Injury & No \\
\hline Fall & 228 \\
\hline RTA & 147 \\
\hline Misc & 57 \\
\hline
\end{tabular}

Table 4: Mode of head injury.

Out of these normal scans were seen in 139 patients. EDH was seen in 87 patients. SDH was in 61. SAH was seen in 31 . IVH was seen in 03 patients. ICH \& Contusions was observed in 73. Cerebral edema was shown in 11 cases. Skull fractures were seen in 179 table 5.

\begin{tabular}{|c|c|c|}
\hline S. No & CT Finding & No of Cases \\
\hline 1 & Normal scans & 139 \\
\hline 2 & EDH & 87 \\
\hline 3 & SDH & 61 \\
\hline 4 & SAH & 31 \\
\hline 5 & IVH & 03 \\
\hline 6 & ICH \& Contusions & 73 \\
\hline 7 & Cerebral edema & 11 \\
\hline 8 & Skull fractures & 179 \\
\hline
\end{tabular}

Table 5: CT Findings.

Conservative management was adopted in 352 patients. Surgical intervention was done in 78 cases as per CT findings. Lumbar drains were put in 02 patients with CSF rhinorrhea table 6. ICP insertion was done in all 67 severe head injury patients.

\begin{tabular}{|c|c|c|}
\hline S. No & Type of Management & No of Cases \\
\hline 1 & Conservative & 352 \\
\hline 2 & Surgical intervention & 78 \\
\hline 3 & Lumbar drains & 02 \\
\hline
\end{tabular}

Table 6: Management protocols.

Out of total Improved \& discharged group constituted 353 patients. 17 cases unfortunately died. Group of still inpatients constituted 44 patients mostly vegetative. LAMA (Left Against Medical Advice) group had 09 patients at different stage of treatment. Transferred to other hospital group had 11 patients when no further intervention was planned table 7 .

\begin{tabular}{|c|c|c|}
\hline S. No & Type of Outcome & No of Patients \\
\hline 1 & Improved \& discharged & 353 \\
\hline 2 & Died & 17 \\
\hline 3 & Still inpatients & 44 \\
\hline 4 & LAMA & 09 \\
\hline 5 & Transferred to other hospital & 11 \\
\hline \multicolumn{3}{|c|}{ Table 7: Outcome. } \\
\hline
\end{tabular}

\section{Discussion}

In review of literature we observed that Hendrickson P in 2017 conducted a consensus based treatment protocols in Latin America and emphasized the role of ICP in deciding the management of traumatic severe head injuries [2]. Similarly Abraham P in 2017 studied via a controlled randomized trial the significance of ICP management in head injuries management but outcome via decompressive craniectomy and barbiturate coma alone had a doubtful significance in their study [3]. On the other hand Zhao HX in 2015 studied the role of ICP in deciding the need of doing a decompressive craniectomy in traumatic head injury management after performing initial definitive craniotomy for evacuation of $\mathrm{EDH}, \mathrm{SDH}$ or contusion requirement was in $14 \%$ of their cases [4]. At the same time Phan K in 2017 studied the role of decompressive craniectomy versus craniotomy in acute subdural hematoma management and found the outcome better in craniotomy group [5]. We find in other study by Li LM in 2012 in their centre and had found outcome better with decompressive craniectomy in acute subdural hematoma management [6]. Hence institution based protocols gave different outcomes in their type of management. We also observed Shen J reporting in 2013 development of contralateral epidural hematoma following decompressive craniectomy for acute subdural hematoma in 5 of their patients [7]. Katsuji Shima in 2010 analyzed the patients in Japan of head injuries and came with guidelines for their management in Japan perspective as such which was almost similar to the world standards [8]. Pre hospital management by escorting team is also of prime importance and saves the patient from secondary insults especially proper $\mathrm{ABC}$ management as stressed by Tentillier E in 2000 [9]. Role of other organ injury in outcome we found in the study by Sarrafzadeh AS in 2001 who studied the outcome in severe head injury alone and patients with severe head injury with polytrauma involving other organ injuries and did not find any major difference [10]. Hsiang JK in 1994 studied whether muscle relaxants are must in severe head injury patient to decrease ICP and came out with conclusions that sedation alone give the same outcome hence not recommended protocol which is followed all over and our institution is not an exception [1].

\section{Conclusion}

To conclude the management of head injuries in our center had been done in conventional internationally accepted protocols. ICP insertion in severe head injury patients was done in diffuse axonal injuries or borderline surgical cases to decide surgery. Outcome had been as per other studies. We did not have any patient developing postoperative contralateral EDH after decompressive craniectomy as described in some studies and our outcome was fair in such cases. However decompressive craniectomy we reserved for acute unilateral 
brain swelling and outcomes were good. Hence head injury management is a challenge and should be done by following the evidence based medicine derived protocols to have an upper hand in patient care.

\section{References}

1. Hsiang JK, Chesnut RM, Crisp CB, Klauber MR, Blunt BA, et al. (1994) Early, routine paralysis for intracranial pressure control in severe head injury: is it necessary?. Crit Care Med 22: 1471-1476.

2. Hendrickson P, Pridgeon J, Temkin NR, Videtta W, Petroni G, et al. (2017) Development of a Severe Traumatic Brain Injury Consensus-Based Treatment Protocol Conference in Latin America. World Neurosurgery 110: 952-957.

3. Abraham P, Rennert RC, Gabel BC, Sack JA, Karanjia N, et al. (2017) ICP management in patients suffering from traumatic brain injury: a systematic review of randomized controlled trials. Acta Neurochir (Wien) 159: 2279-2287.

4. Zhao HX, Liao Y, Xu D, Wang QP, Gan Q, et al. (2015) The value of intraoperative intracranial pressure monitoring for predicting re-operation using salvage decompressive craniectomy after craniotomy in patients with traumatic mass lesions. BMC Surg 15: 111
5. Phan K, Moore JM, Griessenauer C, Dmytriw AA, Scherman DB, et al (2017) Craniotomy Versus Decompressive Craniectomy for Acute Subdural Hematoma: Systematic Review and Meta-Analysis. World Neurosurg 10: $677-685$.

6. Li LM, Kolias AG, Guilfoyle MR, Timofeev I, Corteen EA, et al. (2012) Outcome following evacuation of acute subdural haematomas: a comparison of craniotomy with decompressive craniectomy. Acta Neurochir (Wien) 154: 1555-1561.

7. Shen J, Pan JW, Fan ZX, Zhou YQ, Chen Z, et al. (2013) Surgery for contralateral acute epidural hematoma following acute subdural hematoma evacuation: five new cases and a short literature review. Acta Neurochir (Wien) 155: 335-41.

8. Shima K, Aruga T, Onuma T, Shigemori M, Members of the Japanese Guidelines Committee and The Japan Society of Neurotraumatology (2010) JSNT-Guidelines for the management of severe head injury (Abridged edition). Asian J Neurosurg 5: 15-23.

9. Tentillier E, Ammirati C (2000) [Prehospital management of patients with severe head injuries]. Ann Fr Anesth Reanim 19: 275-281.

10. Sarrafzadeh AS, Peltonen EE, Kaisers U, Küchler I, Lanksch WR, et al. (2001) Secondary insults in severe head injury--do multiply injured patients do worse?. Crit Care Med 29: 1116-1123. 


\section{H \\ детам}

Addiction \& Addictive Disorders

Advances in Industrial Biotechnology

Advances in Microbiology Research

Agronomy and Agricultural Science

AIDS Clinical Research \& STDs

Alcoholism, Drug Abuse \& Substance Dependence

Allergy Disorders and Therapy

Alternative, Complementary \& Integrative Medicine

Alzheimer's \& Neurodegenerative Diseases

Anesthesia \& Clinical care

Angiology \& Vascular Surgery

Animal Research and Veterinary Science

Aquaculture \& Fisheries

Archives of Urology

Archives of Zoological Studies

Atmospheric \& Earth Sciences

Biotech Research \& Biochemistry

Brain \& Neuroscience Research

Cancer Biology and Treatment

Cardiology and Neurocardiovascular Diseases

Cell Biology \& Cell Metabolism

Clinical Dermatology and Therapy

Clinical Immunolgy \& Immunotherapy

Clinical Studies and Medical Case Reports

Community Medicine \& Public Health Care

Current Trends: Medical \& Biological Engineering

Cytology \& Tissue Biology

Dentistry: Oral Health \& Cosmesis

Diabetes \& Metabolic Syndrome Disorders

Emergency Medicine, Trauma and Surgical Care

Environmental Science: Current Research

Food Science \& Nutrition

Forensic, Legal \& Investigative Sciences

Gastroenterology \& Hepatology Research
Genetics \& Genomic Sciences

Gerontology \& Geriatric Medicine

Hematology, Blood Transfusion \& Disorders

Hospice \& Palliative Medical Care

Human Endocrinology

Infectious \& Non Infectious Diseases

Internal Medicine and Primary HealthCare

Laser Research \& Applications

Medicine: Study \& Research

Modern Chemical Sciences

Nanotechnology: Nanomedicine \& Nanobiotechnology

Neonatology and Clinical Pediatrics

Nephrology \& Renal Therapy

Non-invasive Vascular Investigations

Nuclear Medicine, Radiology \& Radiation Therapy

Obesity \& Weight Loss

Ophthalmology \& Clinical Research

Orthopedic Research \& Physiotherapy

Otolaryngology, Head and Neck Surgery

Pathology: Clinical \& Medical Research

Pharmacology, Pharmaceutics \& Pharmacovigilance

Physical Medicine, Rehabilitation \& Disabilities

Plant Science: Current Research

Practical and Professional Nursing

Protein Research \& Bioinformatics

Psychiatry, Depression and Anxiety

Pulmonary Medicine \& Respiratory Research

Reproductive Medicine, Gynaecology and Obstetrics

Stem Cells Research, Development \& Therapy

Surgery: Current Trends \& Innovations

Toxicology: Current Research

Translational Science and Research

Vaccines Research and Vaccination

Virology \& Antivirals 